\title{
Reproductive strategy and lipid mobilization in Rana hexadactyla at a seasonal locality
}

\author{
INDRANEIL DAS ${ }^{1}$ \\ Animal Ecology Research Group, Department of Zoology, University of Oxford, South \\ Parks Road, Oxford OX1 3PS, United Kingdom
}

Received 4 October 1994, accepted 7 October 1995

The reproductive strategy of the folivorous Indian green frog (Rana hexadactyla) was studied at a seasonal locality in south India. The reproductive tracts of adult females, and the liver and abdominal fat masses of adult males and females, were examined monthly. Mature eggs were recovered from females at all months of the year, although monthly variation in relative clutch mass suggests seasonality in reproduction. Egg masses increase prior to the seasonal rains, and drop sharply during or just after the wet seasons. The size of visceral lipid deposits shows seasonal peaks that are correlated to feeding peaks. The decline in fat body mass is associated with spawning peaks, suggesting their mobilization for reproduction. The liver mass of adult males also shows seasonal variation, being greatest prior to the peak spawning periods, indicating the mobilization of lipid for courtship and spermatogenesis. The liver mass of adult females does not show month-to-month variation.

In conclusion, lipids stored in the body as visceral fat are probably not for maintenance during periods of stress but utilized for reproduction by both males and females of Rana hexadactyla. On the other hand, lipid in the liver bodies are utilized only by the males for reproductive activities.

KEY WORDS: diet, reproduction, fat, Rana hexadactyla, seasonality.

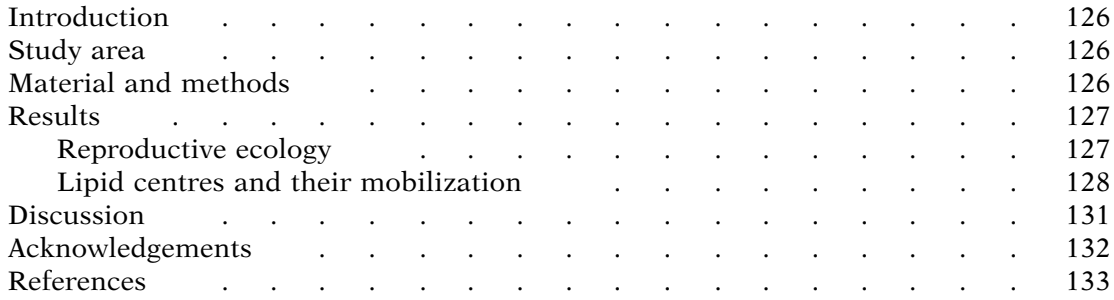

${ }^{1}$ Present address: Museum of Comparative Zoology, Harvard University, 26 Oxford Street, Cambridge, MA 02138, USA. 